\title{
A systems framework for planning and evaluating capacity development in conservation: recommendations for practitioners
}

\author{
Ana L. Porzecansit, Eleanor J. Sterling, Jamieson A. Copsey \\ Michael R. Appleton, James R. Barborak, Brett L. Bruyere, Nora Bynum \\ Kay H. Farmer, Ryan Finchum, Domoina Rakotobe \\ RiCardo B. STANoss and ARMando VALdés-VELÁSQUEZ
}

\begin{abstract}
Capacity development is increasingly recognized as central to conservation goals. Efforts to develop individual, organizational and societal capacity underpin direct investments in biodiversity conservation and natural resource management, and sustain their impact over time. In the face of urgent needs and increasingly complex contexts for conservation the sector not only needs more capacity development, it needs new approaches to capacity development. The sector is embracing the dynamic relationships between the ecological, political, social and economic dimensions of conservation. Capacity development practitioners should ensure that individuals, organizations and communities are prepared to work effectively in these complex environments of constant change to transform the systems that drive biodiversity loss and unsustainable, unequitable resource use. Here we advocate
\end{abstract}

ANA L. PoRZECANSKI (Corresponding author, (D) orcid.org/0000-0002-5157-4579, alporze@amnh.org) and ElEANOR J. STERLing ((D) orcid.org/0000-0003-26928264) Center for Biodiversity and Conservation, American Museum of Natural History, 200 Central Park West, New York, NY 10024-5102, USA

Jamieson A. Copsey IUCN Species Survival Commission, Conservation Planning Specialist Group, Apple Valley, USA

Michael R. Appleton ((D) orcid.org/0000-0003-1669-162X) Re:wild, Austin, USA

JAMES R. BARBoRAK (D) orcid.org/0000-0003-1235-8707) and Ryan FinCHUM (D) orcid.org/0000-0002-7735-3803) Center for Protected Area Management, Colorado State University, Fort Collins, USA

Brett L. BRuYere (D orcid.org/0000-0001-7802-5468) Human Dimensions of Natural Resources Department, Colorado State University, Fort Collins, USA

Nora Bynum Amazon Center for Environmental Education and Research, Bahama, USA

KaY H. FARMER Wild Ally, Edinburgh, UK

Domoina RAкотове (DD orcid.org/0000-0003-1718-0645) Wildlife Conservation Society, Antananarivo, Madagascar

Ricardo B. Stanoss ((D) orcid.org/0000-0001-8891-1244) Smithsonian National Zoo and Conservation Biology Institute, Washington, DC, USA

ARMANDo VAldÉs-VelásQueZ (D) orcid.org/0000-0003-2450-8645) Laboratory for EcoHealth and Urban Ecology, School of Sciences and Philosophy, Universidad Peruana Cayetano Heredia, Lima, Peru

Received 11 February 2021. Revision requested 27 July 2021.

Accepted 26 October 2021. First published online 1 February 2022. for a systems view of capacity development. We propose a conceptual framework that aligns capacity development components with all stages of conservation efforts, fosters attention to context, and coordinates with parallel efforts to engage across practitioners and sectors for more systemic impact. Furthermore, we highlight a need for practitioners to target, measure and support vital elements of capacity that have traditionally received less attention, such as values and motivation, leadership and organizational culture, and governance and participation by using approaches from psychology, the social sciences and systems thinking. Drawing from conservation and other sectors, we highlight examples of approaches that can support reflective practice, so capacity development practitioners can better understand the factors that favour or hinder effectiveness of interventions and influence system-wide change.

Keywords Capacity development, conservation, evaluation, framework, leadership, learning loops, planning, systems

\section{Introduction}

Capacity development is widely recognized as central to achieving development, conservation, and sustainability goals (UNDP, 2008; Bloomfield et al., 2018; Franco \& Tracey, 2019). Investments in biodiversity conservation and sustainable development have been complemented by growing efforts to advance individual and organizational capacity (Bellamy \& Hill, 2010; Ling \& Roberts, 2012; WCPA, 2015).

The need for conservation capacity development continues to grow and change. The next decade will be pivotal for leveraging the full potential of the global network of protected and conserved areas. Strengthening the effectiveness of existing protected areas (Eklund \& Cabeza, 2016; Gill et al., 2017) and improving the management of new areas to internationally accepted standards will require investments to build new capacity, increase the competency of the existing workforce, and replace staff upon retirement (Coad et al., 2019). Ambitious species-specific goals also 
form part of the post-2020 Global Biodiversity Framework (CBD, 2020). With c. 32,000 species classified as threatened with extinction, this target will demand an exponential scaling up of global capacity.

There is also a pressing need to promote in-country capacity of government employees, local stewards and citizens (WCPA, 2015). Furthermore, the diversity of protected and conserved area governance models and the growing complexity of species conservation projects (McCool et al., 2015; Evans et al., 2017; Copsey et al., 2018) have resulted in a broader constituency of people involved in protecting, managing and interpreting biodiversity. Part of the new complexity includes greater engagement with local stakeholders, including an extension of conservation benefits to meet their interests and needs, and planning jointly at a broader landscape scale with attention to local context and capacity development. In this context, collaborative and multi-stakeholder approaches, as well as locally led efforts, are strongly associated with conservation success (Brooks et al., 2013; Sterling et al., 2017, Dawson et al., 2021), and are becoming the norm for state actors, communities, businesses, user groups and academia (Margerum \& Robinson, 2016; Parker et al., 2018; Thomas \& Mendezona Allegretti, 2020).

New investments in capacity development should acknowledge the dynamic and interlinked nature of the social-ecological systems we live in and depend on. The conservation sector operates within complex systems (contexts with many parts that depend on and interact with each other), and practitioners increasingly seek to embrace their ecological, political, social and economic dimensions (Game et al., 2014; Knight et al., 2019). As we strive to do so, the sector needs leaders and practitioners at all levels with the expertise to execute conservation action and act as systems thinkers, adaptive learners, conveners, network builders, collaboration brokers, effective communicators and innovators (Black \& Copsey, 2014; Sawrey et al., 2017; Bruyere et al., 2020).

Systems thinking is both 'an approach to seeing the world and a set of methods and tools', and comprises a set of complementary analytic skills that help us identify and understand systems, predict their behaviours and devise interventions according to our aims (Betley et al., 2021, p. 9). Seeing the world through a systems lens can make connections and relationships more visible and improve our decision-making abilities; systems thinkers ask broader questions and accept that often there is not a single solution to a problem but a set of linked actions that could guide a system towards a desired outcome (Betley et al., 2021). Using a systems lens to better understand the relationships and feedback loops between social and environmental dimensions can prepare individuals to work effectively in complex and changing contexts, and ultimately to transform the systems that drive biodiversity loss and unsustainable, inequitable resource use and its impacts (Díaz et al., 2019). To meet these challenges, the conservation sector is not only in need of more capacity development, it is in need of new approaches to capacity development.

The author team comprises capacity development practitioners and researchers based in the USA, UK, Peru and Madagascar. Our practice has been informed by substantive capacity development engagements in 106 countries over the course of our careers, representing 260 years of combined experience. Here we discuss what we consider to be some of the most persistent challenges in conservation capacity development and propose a broad conceptual framework to guide capacity development planning and evaluation. Our analysis and proposed framework are based on our joint experience, discussions and lessons learnt, as well as a review of practices from conservation and other sectors.

\section{Persistent conservation capacity development challenges}

Current models guiding capacity development recognize that actions are required at multiple levels, from individuals to society (OECD, 2006; CADRI, 2011). These models encompass an individual, an organizational and a societal or system level. The individual level encompasses the attitudes, skills and knowledge, as well as motivation and self-efficacy (the belief in one's own ability to perform a particular task or skill), that are present in individuals. The organizational level encompasses rules, systems and structures within collective contexts, such as diverse organizations, collaborations and local communities. These include leadership dynamics, evolving workplace cultures, and the ability to produce results and to adapt to change, as well as to provide relevant rewards and incentives. Societal systems act as an enabling environment for capacity development: they are the cultural, social, political, financial/economic, legal and environmental contexts in which individuals and organizations operate, providing both constraints and opportunities (UNDP, 2008; CADRI, 2011; Fig. 1). A range of capacity development activities are typically carried out at each of these levels (Table 1).

Although practitioners recognize linkages between individuals, organizations and societal systems, as well as the need to strengthen capacity at these multiple levels, we argue that prevailing planning, evaluation and learning practices in conservation capacity development currently limit our ability to assess effectiveness at each of these levels, and to learn from implementation. Here we discuss two persistent challenges we have identified pertaining to conservation capacity development. 


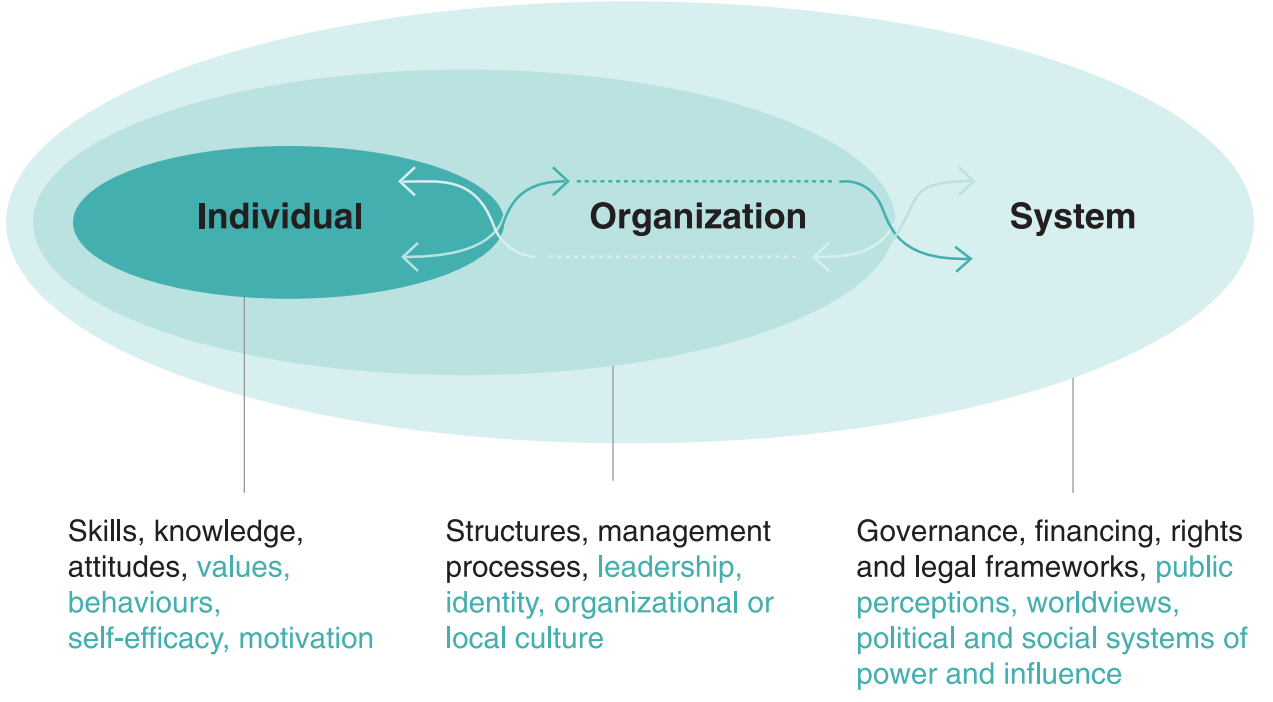

FIg. 1 Practitioners recognize the need to address capacity at multiple levels (represented in this figure by ovals; see text for details). These levels are nested and connect in multiple ways and directions (shown by arrows depicting both direct and indirect linkages as solid and dashed, multidirectional lines, respectively). Relevant dimensions of capacity at each level are indicated below each oval; some are often recognized and targeted (black text), whereas others are less visible and have traditionally received less attention (lighter text).

TABLE 1 Examples of methods for developing capacity at the individual, organization and community, and societal levels. Although many of these approaches can be used at all three levels, we have listed them here under the level where they are most commonly employed. For useful illustrations of some of these methods see WCPA (2015), Bloomfield et al. (2018), Knight et al. (2019) and O'Connell et al. (2019a).

\begin{tabular}{ll}
\hline Level & Methods \\
\hline Individuals & $\begin{array}{l}\text { Conferences, formal education, informal education, mentoring \& coaching, needs assessments, peer-to-peer } \\
\text { learning, self-directed learning, training courses, workshops }\end{array}$ \\
$\begin{array}{l}\text { Organizations } \\
\text { \& communities }\end{array}$ & $\begin{array}{l}\text { Capacity development planning, competences \& standards, demonstration sites, human resource management, } \\
\text { monitoring \& evaluation for organizational learning, networks \& partnerships, operational planning, organizational } \\
\text { assessments, participatory planning \& management, professional \& peer networks, strategic planning, succession } \\
\text { planning, toolkits \& practice guides }\end{array}$ \\
& $\begin{array}{l}\text { Behavioural change interventions (e.g. social marketing campaigns), broad participation in conflict resolution \& } \\
\text { reconciliation processes, cross-sectoral integrated planning, cultural revitalization, institutional analysis, scenario } \\
\text { planning \& modelling, supportive legislation \& policy, systems driver analysis, systems modelling \& analysis }\end{array}$ \\
\hline
\end{tabular}

The need to understand context and clarity of purpose in planning stages

Under a so-called ripple model, the impacts of interventions at the individual level are expected to be far-reaching over time (James, 2009). In our experience, this model informs prevailing planning philosophies such that capacity development interventions target singular aspects of the wider system (predominantly individuals), frequently with an implicit belief that this will lead to change throughout other parts of the system.

Capacity development efforts have documented the advancement and increasing influence of individuals trained over time as they come to occupy leadership positions (e.g. Bravo et al., 2016; Sawrey et al., 2017), but connections to biodiversity outcomes are infrequently documented or evaluated, making it challenging to assess whether a ripple effect occurs. The field would benefit from clearer definitions of capacity targets, envisioned capacity outcomes, as well as the alignment between these and conservation outcomes.
In addition, capacity development programmes are often short-term or centred on single events as opposed to longerterm processes, planned with a limited understanding of local needs and priorities, or in isolation from other related efforts. This can stem from the need to work efficiently, with limited resources and under tight project timescales, but can reduce impact and relevance or even cause unintended harm. For example, the Game Rangers Association of Africa has expressed concerns regarding militarized training of rangers, in which foreign and/or military contractors can lack understanding and appreciation of the political, cultural and social environment in which local rangers operate (GRAA, 2017). A broader lens that involves an understanding of the governance and social-cultural context would provide more opportunities to design actions that are the best fit for a given context, share lessons and coordinate actions with sectors beyond conservation.

Increased attention is needed regarding how we can effectively target, measure and support less visible but vital elements of capacity, such as values and motivation, 
leadership and organizational culture, and governance, by using approaches from psychology and the social sciences. Indicators of psychological capacity such as meaningful ownership, effective autonomy and feeling needed are informative regarding capacity at the individual level and increasingly recognized in conservation (Black \& Copsey, 2014; Cranston, 2016). At a collective level, capacity can be targeted and assessed using indicators of organizational or community capacity. Mumaw et al. (2019) for example, proposed a systems-based framework for community capacity with indicators in five categories: human capital, sociocultural capital, natural capital, economic capital and conservation action. At a societal level, we see a need for diverse indicators that assess collective capacity to target and measure those aspects of human-environmental systems that affect biodiversity loss. Narrow assumptions about collective values and motivations, omissions or limited framings can lead to missed opportunities for crucial capacity development. For example, Agol et al. (2014) have examined context-specific sustainability indicators (i.e. income-generating activities, presence of community-based groups, welfare index, disease incidence, women's leadership). Similarly, Sterling et al. (2020) have highlighted important dimensions contributing to sustainability that are overlooked in many global metric frameworks. Finally, including different systems of knowledge and learning (Reid et al., 2021) in capacity development would enrich these initiatives, diversify measures of success and reduce some of the barriers to the exchange of information, skills and practices.

\section{Evaluating for outcomes and impact}

The evaluation of capacity development is evolving. There is a desire to document results beyond outputs, towards outcomes and system impacts, but in our experience this has proved challenging. It is common for a project to target individuals with the intention of producing conservation or organizational gains, but then report only on outputs (e.g. people trained or events held) or the results of specific activities (e.g. satisfaction with a given course) with no subsequent evaluation of larger or longer-term impacts (Simister \& Smith, 2010). Given that individuals are likely to participate in multiple capacity development events over time, it is more realistic to document contributions to outcomes than to attribute such changes to specific interventions (Mayne, 2008; Simister \& Smith, 2010; Vallejo \& Wehn, 2016), something that both practitioners and donors should take into account. A broader, or systems lens on evaluation would assess capacity development impacts across capacity levels, how changes within levels influence each other, and what is needed for systemic change to occur (Knight et al., 2019).
Some recent evaluations of long-running capacity development programmes reveal the critical role of context, or the enabling environment, which can either facilitate or act as a constraint to change (see below, and Table 2). For example, such barriers may take the form of recruitment, promotion, inclusion and retention policies. A recent evaluation of a long-term training programme in Mauritius shows that if a trainee's work environment was negative, the impact of training on practical skills, job performance and trainee perception of control was lower (Sawrey et al., 2017). Multi-level, longer-term evaluation frameworks would help shed light on the existence of organizational and/or systemic barriers that must be addressed for the potential of individual capacity gains to be fully realized. In summary, we see critical needs and opportunities to adapt how we currently plan, evaluate and learn from capacity development practice in conservation.

\section{A broader conceptual framework to guide capacity development planning and evaluation}

Based on our collective experience and our review of practices from conservation and other sectors, we have organized these ideas into a framework, comprising four stages: preparing, planning and designing, implementing and monitoring, and evaluating and learning (Fig. 2). Our framework is informt by lessons learnt from capacity development efforts in other fields, including health/medicine (LaFond et al., 2002) and economic development (Ling \& Roberts, 2012) as well as literature on learning loops and their application to natural resource management (Kohl \& McCool, 2016), which provide useful ideas for practitioners in the conservation arena.

\section{Discussion}

The framework builds on established steps for planning and programme implementation such as adaptive management (McCarthy \& Possingham, 2009; Keith et al., 2011), the Conservation Standards (CMP, 2020), international guidelines for species conservation planning (IUCN-SSC, 2017), and the principles and steps that underpin participatory planning approaches. The framework aims to foster capacity development efforts that are: (1) aligned and interwoven with the planning and implementation of conservation activities, and (2) conceived using a systems lens, such that efforts consider pre-existing and concurrent efforts, as well as other levels of influence (individuals, organizations, societal systems) as both important context and an opportunity for impact.

If we have reason to believe that achieving conservation outcomes requires coordinated capacity change at multiple levels of a system, or across sectors, then we need to be more 
TABLE 2 Examples of conservation capacity development initiatives that have used double or triple loop learning to examine effectiveness and system-wide implications, and key lessons learnt.

\begin{tabular}{ll}
\hline Context & Learning question \& approach \\
\hline $\begin{array}{ll}\text { The Conservation Planning Specialist Group } \\
\text { of the IUCN's Species Survival Commission }\end{array}$ & $\begin{array}{l}\text { Are there knowledge gains \& changes in } \\
\text { working practice? A 2020 alumni }\end{array}$ \\
has led stakeholder-inclusive species conser- & survey addressed the programme's early \\
vation planning worldwide for 40 years & effectiveness \& also aimed to inform future \\
(CPSG, 2020). In 2018 CPSG formalized its & development. A questionnaire was sent to \\
training programme in species conservation & $>500$ participants on a range of factors: recall \\
planning (online \& in-person) \& mentoring & \& application of training topics, self-efficacy, \\
to build participants' competence \& & motivation, peer networks.
\end{tabular}
confidence.

Colorado State University \& the U.S. Forest Service International Programs Office have led short-term training courses for protected area managers for $>3$ decades, including the International Spanish-language Seminar on Protected Area Management (WCNR, 2020).

In 2003 the Center for Biodiversity \& Conservation of the American Museum of Natural History \& partners led conservation capacity development activities in Madagascar as the Réseau des Educateurs et Professionnels de la Conservation. Focus was to strengthen long-term capacity for biodiversity conservation through the expansion \& enhancement of training opportunities for universities \& conservation professionals (REPC-MD, 2020).

The Wildlife Conservation Society established a network of terrestrial protected area professionals, the Lafa Forum (Lafa Forum, 2020), to advance capacity in protected area management in Madagascar.

A project led by the Propark Foundation (Romania) assessed the individual capacity of $>1,400$ individual protected area staff in 23 countries in Eastern Europe \& the Caucasus using a standard set of competences. Follow-up projects with selected countries focused on developing nationally-owned capacity development strategies for protected area personnel.
How can we evolve our strategy to ensure trainees overcome external barriers? Evaluations showed that trainees faced barriers to implementation \& advancement post-course. The programme now holds pre-course virtual orientations, requires trainees \& superiors to sign pre-course agreements to plan how new skills will be applied \& participate in virtual communities of practice $\&$ reunions.

Is the programme addressing needs \& resulting in lasting change? Needs assessments found a gap between academic courses \& conservation practices. Malagasy conservation educators \& trainers developed modular, locally relevant, open resources on priority topics, $\&$ assessed their use over time. To embed capacity development in-country, the project fostered the development of national competency standards for protected area staff \& establishment of local training programmes for protected area staff, university educators \& community leaders.

\section{Is the project improving performance of} protected area staff? Is this leading to organizational or systemic capacity gains? Needs assessments identified strategies, including workshops, exchange visits between protected area professionals \& small group discussions. Professionals from a variety of public organizations \& NGOs benefited. In 2019, a survey \& focus groups explored changes in protected area management practices.

Are individual capacity gains leading to organizational or systemic capacity gains? In Croatia the capacity planning process was used to leverage funding from a UNDP-GEF project to institutionalize \& operationalize the plan. This led to a shift from reliance on externally driven capacity development projects to better institutional ownership \& leadership of its capacity priorities \& programmes, adoption of new approaches to capacity development, \& adjustment of personnel systems to enable this.
Key lessons

Results supported programme effectiveness yet found knowledge gain was a poor predictor of any of 12 species conservation actions \& had a modest effect on other variables. Self-efficacy was the strongest predictor of most behavioural variables (e.g. motivation). A focus on knowledge is unlikely to elevate competencies or change working practices.

Identifying potential barriers to implementation from the onset helps participants shape action plans that are realistic \& within existing institutional contexts. In addition to technical skills, it is critical to develop self-efficacy. Trainee-supervisor agreements can foster a more supportive environment \& create a positive feedback loop for further investments in capacity development.

The programme assessed capacity needs, convened key players to invest in strategic long-term thought \& worked to implement solutions at the individual, organizational \& national levels. Frequent evaluation of results \& co-adaptation of project targets \& goals enabled the initiative to achieve impact across scales \& systemically. The competence standards now serve as a tool for performance evaluation, design of training curriculum \& career development paths \& for recruitment in the field of protected area management in Madagascar.

A majority of participants (82\%) reported major improvements in the way they work. There was little evidence that these changes have been incorporated by their organizations but there was a significant perception of positive changes such as more integrated activities among departments \& across hierarchies. Longer project duration would have allowed measurement of additional impacts.

Project success was highly reliant on institutional change-readiness \& building trust \& collaboration with partners. Individual capacity assessments \& the engagement of human resource departments stimulated an interest in finding broader ways to address shortcomings. The process of capacity development planning triggered a conceptual leap from listing training needs to changing how the institution addressed capacity in a broader way. 
TABLE 2 (Cont.)

\begin{tabular}{|c|c|c|}
\hline Context & Learning question \& approach & Key lessons \\
\hline $\begin{array}{l}\text { The Orangutan Veterinary Advisory Group } \\
\text { leads capacity development for wildlife } \\
\text { veterinarians in Indonesia \& Malaysia, link- } \\
\text { ing wildlife, public \& ecosystem health. } \\
\text { Activities include didactic \& problem-based } \\
\text { workshops, practical labs, online advisory } \\
\text { support, \& acting as an advocate between } \\
\text { participants \& their organizations } \\
\text { (Unwin et al., 2021). }\end{array}$ & $\begin{array}{l}\text { What are the gains \& changes in working } \\
\text { practice? Participants complete an annual } \\
\text { survey on application of new knowledge or } \\
\text { ideas, improvements to job performance } \\
\text { \& the health of animals, \& knowledge sharing. } \\
\text { Evaluations show high value to participants, } \\
\text { a sense of higher efficacy \& significant } \\
\text { improvements in conservation medicine \& } \\
\text { wildlife clinical skills. An unexpected impact } \\
\text { is helping mitigate issues of burnout, \& } \\
\text { fostering job retention. Participation is } \\
\text { recognized by a local professional } \\
\text { association, serving to steer standards in } \\
\text { formal education. }\end{array}$ & $\begin{array}{l}\text { The project has improved disease sur- } \\
\text { veillance, risk analysis \& clinical skills. } \\
\text { External barriers such as limited profes- } \\
\text { sional progression \& rigid organizational } \\
\text { structures show a need to provide effec- } \\
\text { tive well-being \& advocacy support with } \\
\text { employers \& professional associations, \& } \\
\text { the importance of institutional readiness } \\
\text { to adopt \& adapt to new ways of working. } \\
\text { Although the impact of the Group on } \\
\text { enhancing conservation health \& medi- } \\
\text { cine knowledge \& skills can be measured, } \\
\text { evaluating the impact on orangutan con- } \\
\text { servation requires long-term data collec- } \\
\text { tion \& presents the challenge of assessing } \\
\text { attribution. }\end{array}$ \\
\hline
\end{tabular}

Through a careful, context-informed, collaborative design, a capacity development programme of the Saint Lucia Forestry Department was reoriented from a focus on developing a protected area management plan to a focus on broad organizational capacity development (Appleton et al., 2017).
What has been done \& what is needed? Initial plans focused on improving understanding of technical requirements for management \& protection, but discussions led to a realization that the more fundamental need was to examine the institution \& its operations. Participatory individual \& organizational capacity assessments were conducted with external support, leading to development of an entirely new organizational strategy. This is now used in Saint Lucia as a guide for similar processes in other departments.
The key to success was the readiness of the organization for change \& the openness of its leadership towards listening to staff \& embracing change. Engagement of Forestry Department staff was a capacity development process in itself \& helped build institution-wide ownership of the process \& results. The process advanced thinking to consider the capacity of the institution to function effectively, \& ultimately to revising the goals, objectives \& structure of the department. explicit in designing and evaluating capacity development activities in this way, a radical departure from how conservation capacity development is typically carried out. Causal models, or theories of change (models that 'detail the logic and assumptions around how a series of interdependent steps will lead to intended outcomes'; Cheng et al., 2020, p. 2), are a potentially helpful way to make our expectations explicit about the effects of an intervention and the role of all actors in a system. Theories of change need to be welldefined, and their assumptions and pathways should be logical and plausible (Aragón, 2010; Mayne, 2017; Cheng et al., 2020). However, capacity development causal models currently tend to focus mostly on individuals, presenting a bias towards the more visible aspects of capacity, such as training for knowledge gains, application or strategic planning (e.g. see capacity development theories of change in the Conservation Actions \& Measures Library; CAML, 2020).

Another useful idea, that of learning loops (Argyris, 1977; Hargrove, 2002), has been increasingly applied to natural resource management to capture the need for different kinds of learning (see Kohl \& McCool, 2016; O'Connell et al., 2019a). Authors identify three kinds of learning loops: single loop learning adjusts and refines existing practices (i.e. asks: Are we doing things right? Are we efficient?), and double loop learning reframes or reforms assumptions, goals and strategies (Are we doing the right things? Are we effective?). Finally, triple-loop learning entails questioning our goals and assumptions about the way things are and should be, and leads to further transformation of worldviews and values (Are we pursuing the right outcomes? Are we asking the right questions?). The framework and questions for practitioners that we present here aim to foster learning along all three loops.

Practitioners from the field of human development have framed capacity development as a complex process of change, with a focus on individuals or groups as change agents, perhaps not ripples activated by an external intervention but rather capable of initiating and generating their own ripples, and even chain reactions. In recognition of the long timeframes of capacity development, there is an increasing focus on monitoring and evaluating intermediate capacity outcomes that can facilitate or drive further change. The World Bank Institute defines these as improvements in the ability or disposition of the local change agents to take actions that will effect institutional changes towards a development goal' (Ling \& Roberts, 2012, p. 15). They illustrate six types of intermediate capacity outcomes: raised awareness, enhanced knowledge or skills, improved consensus and teamwork, strengthened coalitions, enhanced networks and new implementation know-how. Combined 


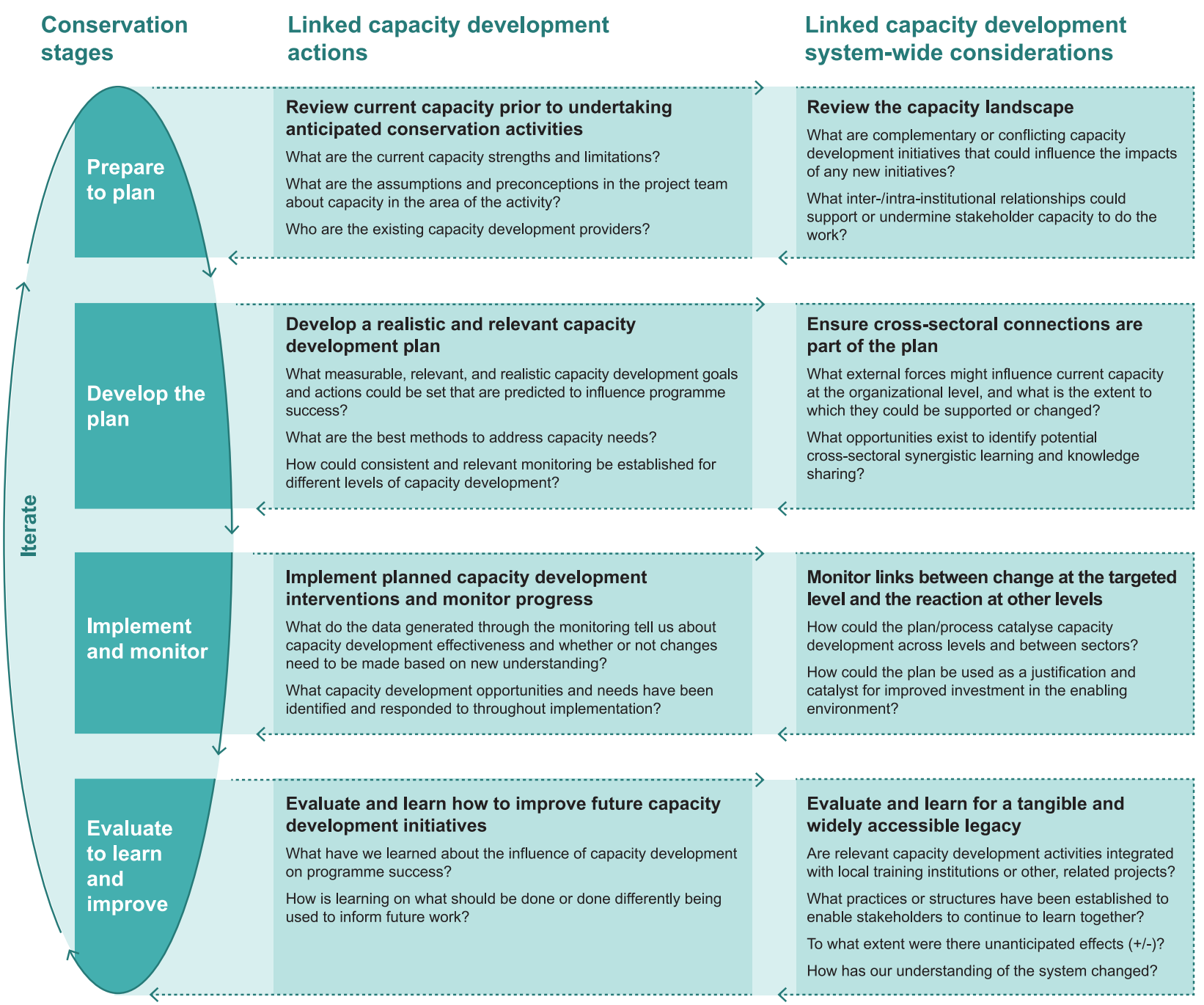

FIG. 2 A conceptual framework for an iterative, multi-loop learning process for conservation and capacity development planning, implementation and evaluation. The framework lays out guiding questions that can help connect conservation actions at different stages to capacity development actions and cross-level, cross-sectoral considerations, to catalyse learning at multiple levels during the capacity development process. For our purposes we view a stakeholder as being an individual or an organization that has a vested interest in or power over the plan to be implemented.

with resources (financial, human, technology and infrastructure), these types of outcomes are expected to lead to changes in institutional capacity over longer time frames yet can be assessed in the medium term, and could be useful for conservation.

In conservation, we see capacity development practitioners using double loop learning through adaptive management and reflection (Manolis et al., 2009; Black, 2019). There is also a growing emphasis on assessing results in terms of both outputs and outcomes (Howe \& MillnerGulland, 2012). Some practitioners are striving to measure learning and competence outcomes beyond outputs, including whether the learning was retained and applied later (Sawrey et al., 2017).

In addition, there is increasing reflection about the capacity development methods used, the things we are doing, because as conservation strategies diversify, methods may not be optimal for the full diversity of participants. For example, many capacity development activities aimed at protected area management or species conservation have focused on short-term, one-off training events, or on academic programmes (Elliott et al., 2018), which often focus on research training. Although this strategy is adequate for some capacity development objectives, it may not be effective for all. Training courses continue to have an important role, and additional approaches to learning such as mentoring and regional networks can fulfil a learning need that formal training courses cannot (Pietri et al., 2015; O'Connell et al., 2019b).

We recommend that practitioners reflect on their work by asking questions at each stage of conservation to promote a broader lens for the design, implementation and evaluation of capacity development in conservation; illustrative questions are included in Fig. 2. We have aimed to 
include triple loop questions in our framework through cross-level considerations and stage 4, Evaluate to learn and improve (Fig. 2). Sterling et al. (2021) provide an analysis of the current state of capacity development evaluation, and highlight the need for systems approaches to evaluation that explore the links between interventions and effects at other levels, including effects on biodiversity and other outcomes. The considerations and questions outlined in our framework can help orient practitioners towards envisioned outcomes, and encourage the monitoring of peer efforts, consideration of broader contexts and evaluation at all levels through cycles of reflection and learning (Manolis et al., 2009). The framework is meant to be applied in an iterative way, promoting evaluation cycles.

To connect these ideas to capacity development practice, we have compiled selected, illustrative examples of conservation capacity development projects to explore how they have applied double and triple loop learning (Table 2). These examples support the practitioner recommendations presented in the framework and highlight several lessons for practitioners. A number of examples support targeting more than gains in knowledge and technical skills and highlight the importance of monitoring dimensions such as individual confidence and self-efficacy, and even the holistic wellbeing of practitioners. Most examples also demonstrate a need to engage with the broader context of the work and with stakeholders in all stages. This is especially important in capacity development, given that important barriers to efficacy can stem from rigid or organizational cultures and structures.

Several of the examples demonstrate the enabling influence of learning spaces where it is safe to experiment and try out new methods, tools and practices within organizations and across them, through networks. The readiness for change of organizations and systems should be an important focus for conservation moving forward. This can be advanced by both practitioners and donors by promoting monitoring and evaluation approaches that focus on learning, and include learning from failure (Redford \& Taber, 2000; Knight et al., 2019).

\section{Conclusion}

As we face a shifting understanding of the social and ethical context for conservation, updated modes of leadership, and the limitations of conventional planning practices for the complexities and needs of our time, there is a pressing need to evolve capacity development practice in conservation. Our aim was to highlight how this new understanding can apply to capacity development planning, spark discussion of an initial conceptual model, and promote its testing and refinement in the design and delivery of programmes. The framework we present here describes conservation capacity development as a cyclical and ongoing process that includes opportunities for stakeholders to engage in collective reflection and learning from experience. Convening together, for instance through ongoing communities of practice at local and regional scales or through dedicated gatherings for directed reflection could help create spaces for this type of collective exchange.

The hard questions inherent in double and triple loop learning demand significant time, attention and resources, possibly resulting in major restructuring, and diverting time from other activities. Yet some of the most fundamental questions around conservation capacity development are double and triple loop questions: Does capacity development contribute to achieving conservation goals? Does the evidence demonstrate it leads to impact? Does it empower individuals and organizations to lead transformational change? Asking, and endeavouring to answer, these questions will strengthen the case for capacity development and its value, as well as conservation practice.

Acknowledgements We thank colleagues at the IUCN World Commission of Protected Areas and our institutions, who have discussed these ideas with us over the years. We thank N. Gazit for valuable assistance with figures, and the Editor and an anonymous reviewer for their helpful comments. This research received no specific grant, commercial or not-for-profit funding.

Author contributions Developing the content, writing: all authors.

\section{Conflicts of interest None.}

Ethical standards This research abided by the Oryx guidelines on ethical standards.

\section{References}

Agol, D., Latawiec, A.E. \& Strassburg, B.B. (2014) Evaluating impacts of development and conservation projects using sustainability indicators: opportunities and challenges. Environmental Impact Assessment Review, 48, 1-9.

Appleton, M.R., Daltry, J. \& Toussaint, A. (2017) From forestry to protected area and ecosystem management: organisational change in Saint Lucia, West Indies. Parks, 23, 51-62.

Aragón, A.O. (2010) A case for surfacing theories of change for purposeful organisational capacity development. IDS Bulletin, $41,36-46$.

Argyris, C. (1977) Double loop learning in organizations. Harvard Business Review, 55, 115-125.

Bellamy, J. \& Hill, K. (2010) National Capacity Self-Assessments: Results and Lessons Learned for Global Environmental Sustainability. Global Support Programme, Bureau for Development Policy, United Nations Development Programme, New York, USA.

Betley, E., Sterling, E.J., Akabas, S., Paxton, A. \& Frost, L. (2021) Introduction to systems and systems thinking. Lessons in Conservation, 11, 9-25.

BLACK, S. (2019) Psychological knowledge relevant to leadership in wildlife conservation. Open Journal of Leadership, 8, 114-141.

Black, S.A. \& Copsey, J.A. (2014) Purpose, process, knowledge, and dignity in interdisciplinary projects. Conservation Biology, 28, 1139-1141. 
Bloomfield, G., Bucht, K., Martínez-Hernández, J.C., Ramírez-Soto, A.F., Sheseña-Hernández, I., Lucio-Palacio, C.R. et al. (2018) Capacity building to advance the United Nations sustainable development goals: An overview of tools and approaches related to sustainable land management. Journal of Sustainable Forestry, 37, 157-177.

Bravo, A., Porzecanski, A.L., Valdés-Velásquez, A., Aguirre, L.F., Agullera, G., Arrascue, A. et al. (2016) Strengthening capacity for biodiversity conservation in the southern tropical Andes through partnerships of educators and practitioners. In Tropical Conservation: Perspectives on Local and Global Priorities. 1st edition (eds A.A. Aguirre, R. Sukumar \& R.A. Medellín), pp. 417-429. Oxford University Press, Oxford, UK.

Brooks, J., Waylen, K.A. \& Mulder, M.B. (2013) Assessing community-based conservation projects: a systematic review and multilevel analysis of attitudinal, behavioral, ecological, and economic outcomes. Environmental Evidence, 2, 1-34.

Bruyere, B., Bynum, N., Copsey, J., Porzecanski, A. \& Sterling, E. (2020) Conservation Leadership Capacity Building: A Landscape Study. Summary of Key Findings. tinyurl.com/y4tnl62r [accessed 1 September 2020].

CADRi (Capacity for Disaster Reduction Initiative) (2011) Basics of Capacity Development for Disaster Risk Reduction. Capacity for Disaster Reduction Initiative. rootchange.org/about_us/resources/ publications/CADRI_brochure\%2ofinal.pdf [accessed 1 May 2020].

CAMl (Conservation Actions and Measures Library) (2020) High Level Standard Results Chain on Evaluation, Effectiveness Measures \& Learning. miradishare.org/ux/program/cmpconservationaction?nav1 $=$ caml-projects [accessed 1 May 2020].

CbD (Convention on Biological Diversity) (2020) Zero Draft of the Post-2020 Global Biodiversity Framework. Convention on Biological Diversity Open-Ended Working Group, Second Meeting, Kunming, China, 24-29 February 2020. cbd.int/doc/c/efbo/1f84/ a892b98d2982a829962b6371/wg2020-02-03-en.pdf [accessed 1 May 2020].

Cheng, S.H., McKinnon, M.C., Masuda, Y.J., Garside, R., Jones, K.W., Miller, D.C. et al. (2020) Strengthen causal models for better conservation outcomes for human well-being. PLOS ONE, 15, e0230495.

CMP (Conservation Measures Partnership) (2020) Open Standards for the Practice of Conservation, Version 4.o. cmp-openstandards.org [accessed 1 May 2020].

Coad, L., Watson, J.E., Geldmann, J., Burgess, N.D., Leverington, F., Hockings, M. et al. (2019) Widespread shortfalls in protected area resourcing undermine efforts to conserve biodiversity. Frontiers in Ecology and the Environment, 17, 259-264.

Copsey, J.A., Black, S.A., Groombridge, J.J. \& Jones, C.G. (eds) (2018) Species Conservation: Lessons From Islands. Cambridge University Press, Cambridge, UK.

CPSG (Conservation Planning Specialist Group) (2020) cpsg.org [accessed October 2020].

CrANSTON, K.A. (2016) Building and measuring psychological capacity for biodiversity conservation. $\mathrm{PhD}$ thesis. Antioch University New England, Keene, USA.

Dawson, N., Coolsaet, B., Sterling, E., Loveridge, R., Gross-Camp, N., Wongbusarakum, S. et al. (2021) The role of indigenous peoples and local communities in effective and equitable conservation. Ecology and Society, 26, 19.

Díaz, S., Settele, J., Brondízio, E.S., Ngo, H.T., Agard, J., Arneth, A. et al. (2019) Pervasive human-driven decline of life on Earth points to the need for transformative change. Science, 366, eaax310o.

Eklund, J. \& CABeza, M. (2016) Quality of governance and effectiveness of protected areas: crucial concepts for conservation planning. Annals of the New York Academy of Sciences, 1399, 27-41.
Elliott, L., Ryan, M. \& Wyвorn, C. (2018) Global patterns in conservation capacity development. Biological Conservation, 221, 261-269.

Evans, M.C., Davila, F., Toomey, A. \& Wyborn, C. (2017) Embrace complexity to improve conservation decision making. Nature Ecology and Evolution, 1, 1588.

Franco, I.B. \& Tracey, J. (2019) Community capacity-building for sustainable development. International Journal of Sustainability in Higher Education, 20, 691-725.

Game, E.T., Meijaard, E., McDonald-Madden, E. \& Sheil, D. (2014) Conservation in a wicked complex world; challenges and solutions. Conservation Letters, 7, 271-277.

Gill, D.A., Mascia, M.B., Ahmadia, G.N., Glew, L., Lester, S.E., BARNES, M. et al. (2017) Capacity shortfalls hinder the performance of marine protected areas globally. Nature, 543, 665-669.

GraA (Game Rangers Association of Africa) (2017) Media statement: The use of military and security personnel and tactics in the training of Africa's Rangers. gameranger.org/news-views/mediareleases/170-media-statement-the-use-of-military-and-securitypersonnel-and-tactics-in-the-training-of-africa-s-rangers.html [accessed 1 May 2020].

Hargrove, R. (2002) Masterful Coaching, Revised Edition. Jossey-Bass/Pfeiffer, Wiley, San Francisco, USA.

Howe, C. \& Milner-Gulland, E.J. (2012) Evaluating indices of conservation success: a comparative analysis of outcomeand output-based indices. Animal Conservation, 15, 217-226.

IUCN-SSC (Species Survival Commission) Species Conservation Planning Sub-Committee (2017) Guidelines for Species Conservation Planning. Version 1.o. Gland, Switzerland: IUCN. iucn.org/theme/species/publications/guidelines [accessed 1 May 2020].

James, R. (2009) Just Do It: Dealing with the Dilemmas in Monitoring and Evaluating Capacity Building. Praxis Note 49. International NGO Training and Research Centre, Oxford, UK.

Keith, D.A., Martin, T.G., McDonald-Madden, E. \& Walters, C. (2011) Uncertainty and adaptive management for biodiversity conservation. Biological Conservation 144, 1175-1178.

Knight, A.T., Cook, C.N., Redford, K.H., Biggs, D., Romero, C., Ortega-Argueta, A. et al. (2019) Improving conservation practice with principles and tools from systems thinking and evaluation. Sustainability Science, 14, 1531-1548.

Kohl, J. \& McCool, S. (2016) The Future Has Other Plans: Planning Holistically to Conserve Natural and Cultural Heritage. Fulcrum Publishing, Golden, USA.

LAFA ForUm (2020) forum-lafa.org [accessed October 2020].

LaFond, A.K., Brown, L. \& Macintyre, K. (2002) Mapping capacity in the health sector: a conceptual framework. The International Journal of Health Planning and Management, 17, 3-22.

Ling, C.M. \& Roberts, D. (2012) Guide to Evaluating Capacity Development Results: A Collection of Guidance Notes to Help Development Practitioners and Evaluators Assess Capacity Development Efforts. The World Bank, Washington DC, USA. documents.worldbank.org/curated/en/352241468163166112/pdf/ 76280oWPoBox37oevelopmentoResultsoo.pdf [accessed October 2020].

Manolis, J.C., Chan, K.M., Finkelstein, M.E., Stephens, S., Nelson, C.R., Grant, J.B. et al. (2009) Leadership: a new frontier in conservation science. Conservation Biology, 23, 879-886.

Margerum, R.D. \& Robinson, C.J. (2016) Introduction: the challenges of collaboration in environmental governance. In The Challenges of Collaboration in Environmental Governance: Barriers and Responses (eds R.D. Margerum \& C.J. Robinson), pp. 1-26. Edward Elgar Publishing, Cheltenham, UK. 
Mayne, J. (2008) Contribution Analysis: An Approach to Exploring Cause and Effect. ILAC Brief No. 16. cgspace.cgiar.org/handle/ 10568/70124 [accessed 11 November 2021].

MAYNE, J. (2017) Theory of change analysis: building robust theories of change. Canadian Journal of Program Evaluation, 32, 155-173.

McCarthy, M.A. \& Possingham, H.P. (2009) Active adaptive management for conservation. Conservation Biology, 21, 956-963.

McCool, S.F., Freimund, W.A. \& Breen, C. (2015) Benefiting from complexity thinking. In Protected Area Governance and Management (eds G.L. Worboys, M. Lockwood, A. Kothari, S. Feary \& I. Pulsford), pp. 291-326. Australian National University Press, Canberra, Australia.

Mumaw, L.M., Maller, C. \& Bekessy, S. (2019) Assessing and strengthening community capacity building in urban biodiversity conservation programs. Cities and the Environment, 12, 4.

O'Connell, D., Maru, Y., Grigg, N., Walker, B., Abel, N., Wise, R. et al. (2019a) Resilience, Adaptation Pathways and Transformation Approach. A Guide for Designing, Implementing and Assessing Interventions for Sustainable Futures (Version 2). Commonwealth Scientific and Industrial Research Organisation, Canberra, Australia. research.csiro.au/eap/rapta [accessed 1 May 2020].

O'Connell, M.J., Nasirwa, O., Carter, M., Farmer, K.H., Appleton, M., Arinaitwe, J. et al. (2019b) Capacity building for conservation: problems and potential solutions for sub-Saharan Africa. Oryx, 53, 273-283.

OECD (Organisation for Economic Cooperation and Development) (2006) The Challenge of Capacity Development: Working Towards Good Practice. OECD Papers, 6, 1-35.

Parker, P.G., Miller, R.E. \& Goodman, S.J. (2018) Collaboration and the politics of conservation. In Disease Ecology: Galapagos Birds and their Parasites (ed. P. Parker), pp. 305-324. Springer Cham, New York, USA.

Pietri, D.M., Stevenson, T.C. \& Christie, P. (2015) The coral triangle initiative and regional exchanges: strengthening capacity through a regional learning network. Global Environmental Change, $33,165-176$.

ReDFord, K.H. \& TABER, S. (200o) Writing the wrongs: developing a safe-fail culture in conservation. Conservation Biology, $14,1567-1568$.

Reid, A.J., Eckert, L.E., Lane, J.F., Young, N., Hinch, S.G., Darimont, C.T. et al. (2021) "Two-eyed seeing": An Indigenous framework to transform fisheries research and management. Fish and Fisheries, 22, 243-261.
REPC-MD (Réseau des Educateurs et Professionnels de la Conservation à Madagascar) (2020) facebook.com/ RepcMadagascar [accessed October 2020].

Sawrey, B., Copsey, J. \& Milner-Gulland, E.J. (2017) Evaluating impacts of training in conservation: a case study in Mauritius. Oryx, 53, 117-125.

Simister, N. \& Smith, R. (2010) Monitoring and Evaluating Capacity Building: Is it Really that Difficult? Praxis paper, 23. International NGO Training and Research Centre, Oxford, UK.

Sterling, E.J., Betley, E., Sigouin, A., Gomez, A., Toomey, A., Cullman, G. et al. (2017) Assessing the evidence for stakeholder engagement in biodiversity conservation. Biological Conservation, 209, 159-171.

Sterling, E.J., Pascua, P., Sigouin, A., Gazit, N., Mandle, L. BetLey, E. et al. (2020) Creating a space for place and multidimensional well-being: lessons learned from localizing the SDGs. Sustainability Science, 15, 1129-1147.

Sterling, E.J., Sigouin, A., Betley, E., Zavalata Cheek, J. Solomon, J., Landrigan, K. et al. (2021) The state of capacity development evaluation in biodiversity conservation and natural resource management. Oryx, published online 21 December 2021.

Thomas, R.E. \& Mendezona Allegretti, A. (2020) Evaluating the process and outcomes of collaborative conservation: tools, techniques, and strategies. Society \& Natural Resources, 33, 433-441.

UndP (United Nations Development Programme) (2008) Capacity Development: Empowering People and Institutions. Annual Report. United Nations Development Programme, New York, USA.

Unwin, S., Commitante, R., Moss, A., Bridges, E., Farmer, K.H., JAYA, R.L. et al. (2021) Evaluating the contribution of a wildlife health capacity building program on orangutan conservation. American Journal of Primatology, published online 21 May 2021.

VAllejo, B. \& WehN, U. (2016) Capacity development evaluation: the challenge of the results agenda and measuring return on investment in the Global South. World Development, 79, 1-13.

WCNR (Warner College of Natural Resources) (2020) warnercnr.colostate.edu/cpam/curso-de-manejo-de-areasprotegidas [accessed October 2020].

WCPA (World Commission on Protected Areas) (2015) A Strategic Framework for Capacity Development in Protected Areas and Other Conserved Territories 2015-2025. cmsdata.iucn.org/ downloads/sfcd_final_july_2015.pd [accessed 1 May 2020]. 